\title{
EXISTENCE OF APPROXIMATE SOLUTION TO ABSTRACT NONLOCAL CAUCHY PROBLEM ${ }^{1}$
}

\author{
L. BYSZEWSKI ${ }^{2}$ \\ Florida Institute of Technology \\ Department of Applied Mathematics \\ 150 West University Blvd. \\ Melbourne, Florida 32901-6988, U.S.A.
}

\begin{abstract}
The aim of the paper is to prove a theorem about the existence of an approximate solution to an abstract nonlinear nonlocal Cauchy problem in a Banach space. The right-hand side of the nonlocal condition belongs to a locally closed subset of a Banach space. The paper is a continuation of papers [1], [2] and generalizes some results from [3].

Key words: Abstract nonlinear nonlocal Cauchy problem, locally closed sets, existence of an approximate solution.

AMS (MOS) subject classifications: $\quad 34 \mathrm{~A} 10,34 \mathrm{~A} 34$, 34A45, 34A99, 34G20, 34G99.
\end{abstract}

\section{INTRODUCTION}

In papers [1] and [2], theorems about the existence and uniqueness of solutions of abstract nonlinear nonlocal Cauchy problems in Banach spaces were considered. To obtain those results, the Banach theorem about the fixed point and the method of semigroups were used. The aim of this paper is to construct an approximate solution to an abstract nonlinear nonlocal Cauchy problem in a Banach space under the assumptions that the right-hand side of the differential equation does not satisfy any kind of the Lipschitz condition and under the assumption that the right-hand side of the nonlocal condition belongs to a locally closed subset of a Banach space. To prove the main result of the paper, a modification of a method used by Lakshmikantham and Leela (see [3], Section 2.6) is applied. To modify the approach by Lakshmikantham and Leela, we construct a special locally closed subset of a Banach space. The paper, analogously as in [1] and [2], can be applied in physics.

\footnotetext{
${ }^{1}$ Received: July, 1992. Revised: October, 1992.

${ }^{2}$ Permanent address: Cracow Technical University, Institute of Mathematics, Warszawska 24, 31-155 Cracow, Poland.
} 


\section{PRELIMINARIES}

Let $E$ be a Banach space with norm $\|\cdot\|$ and let

$$
B(a, \rho):=\{x \in E:\|x-a\| \leq \rho\}
$$

where $a \in E$ and $\rho>0$.

To find an approximate solution for the Cauchy nonlocal problem considered in the paper we shall need the following:

Assumption $\left(A_{1}\right): F$ is a such subset of $E$ that for each $x_{0} \in F$ there exist numbers $r \in(0, \infty)$ and $\epsilon \in(0, r)$, and there exists a sequence $\left\{x_{0}^{i}\right\}_{i=1}^{\infty} \subset F_{0} \backslash\left\{x_{0}\right\}$, where

$$
F_{0}:=F \cap B\left(x_{0}, r\right)
$$

such that

(i) $\quad F_{0}$ is closed in $E$;

(ii) $\quad\left\|x_{0}^{i}\right\| \leq\left\|x_{0}^{i+1}\right\| \leq\left\|x_{0}\right\|$ for all $i=1,2, \ldots$;

(iii) $\left\|x_{0}^{i}-x_{0}\right\| \underset{i \rightarrow \infty}{\longrightarrow} 0$;

(iv) $\quad\left\|x_{0}^{i}-x_{0}\right\|<\epsilon$ for all $i=1,2, \ldots$

It is easy to see that a subset $F$ of a Banach space $E$ satisfying Assumption $\left(A_{1}\right)$ must be a locally closed set.

Now, we shall give two examples.

Example 1: Let $E=\mathbb{R}^{2}$ with the Euclidian norm and let $F=\mathbb{R} \times(0, c]$, where $c$ is a positive real number. Choose an arbitrary point $x_{0}=\left(x_{01}, x_{02}\right)$ from $F$ and choose a number $r$ satisfying the condition $0<r<x_{02}$. Next, choose a number $\epsilon$ such that $0<\epsilon<r<x_{02}$ and define a sequence $\left\{x_{0}^{i}\right\}_{i=1}^{\infty}$, where $x_{0}^{i}=\left(x_{01}^{i}, x_{02}^{i}\right)(i=1,2, \ldots)$, by the formula

$$
x_{01}^{i}:=x_{01} \text { and } x_{02}^{i}:=x_{02}-\frac{\epsilon}{i+1}(i=1,2, \ldots)
$$

Since

$$
\begin{gathered}
0<x_{02}-\frac{\epsilon}{i+1}<x_{02}-\frac{\epsilon}{i+2}<x_{02} \quad(i=1,2, \ldots), \\
\left\|x_{0}^{i}-x_{0}\right\|=\frac{\epsilon}{i+1}(i=1,2, \ldots)
\end{gathered}
$$

and

$$
\left\|x_{0}^{i}-x_{0}\right\| \leq \frac{\epsilon}{2}<\epsilon(i=1,2, \ldots)
$$


then the sequence $\left\{x_{0}^{i}\right\}_{i=1}^{\infty}$ given by (5) satisfies conditions (2), (3) and (4). Additionally, the set $(\mathbb{R} \times(0, c]) \cap B\left(x_{0}, r\right)$ is closed in $E$. Consequently, sets $E$ and $F$ from this example satisfy Assumption $\left(A_{1}\right)$ and, therefore, there exists a nonempty class of subsets $F$ of a Banach space $E$ such that Assumption $\left(A_{1}\right)$ is satisfied.

Example 2: Let $E=\mathbb{R}^{2}$ with the Euclidian norm and let $F=(-\infty, 0] \times(-\infty, 0]$. It is easy to see that for each $x_{0} \in F$ there exists a $r>0$ such that condition (1) from Assumption $\left(A_{1}\right)$ holds, but for $x_{0}=(0,0)$ there is not a sequence $\left\{x_{0}^{i}\right\}_{i=1}^{\infty} \subset F_{0} \backslash\left\{x_{0}\right\}$ such that conditions (2)-(4) from Assumption $\left(A_{1}\right)$ hold simultaneously. Consequently, there exists a locally closed subset of $E$ such that conditions (2)-(4) do not hold for this subset. Therefore, to find an approximate solution for the nonlocal problem considered in the paper, it will be necessary to use Assumption $\left(A_{1}\right)$ in the next section.

In Section 3, under Assumption $\left(A_{1}\right)$ and under some assumptions concerning a function $f$ and the constants $t_{0}, T$ and $k$, an approximate solution for the following abstract nonlocal Cauchy problem

$$
\begin{gathered}
x^{\prime}(t)=f(t, x(t)), t \in\left[t_{0}, t_{0}+T\right] \\
x\left(t_{0}\right)+k x\left(t_{0}+T\right)=x_{0} \in F
\end{gathered}
$$

is studied.

\section{THEOREM ABOUT APPROXIMATE SOLUTION}

Theorem 1: Let $E$ be a Banach space with norm $\|\cdot\|$ and let $x_{0}$ be an arbitrary fixed element of a subset $F$ of space $E$ satisfying Assumption $\left(A_{1}\right)$. Assume, additionally, that

$\left(A_{2}\right) \quad k$ is a constant satisfying the condition

$$
0<|k|<\frac{r-\epsilon}{r-\epsilon+\left\|x_{0}\right\|} .
$$

$\left(A_{3}\right) \quad f \in C\left(\left[t_{0}, t_{0}+T_{0}\right] \times F, E\right)$, where $t_{0}$ is a real constant and $T_{0}$ is a real positive constant.

$\left(A_{4}\right) \quad\|f(t, x)\| \leq M-1$ for $(t, x) \in\left[t_{0}, t_{0}+T_{0}\right] \times F_{0}$, where $M$ is a constant satisfying the inequality $M>1$.

$$
\begin{aligned}
& \left(A_{5}\right) \quad T:=\min \left\{T_{0}, \frac{r-\epsilon}{M}(1-|k|)-\frac{\left\|x_{0}\right\|}{M}|k|\right\} . \\
& \left(A_{6}\right) \lim _{h \rightarrow 0^{+}} \inf \frac{1}{h} d(x+h f(t, x), F)=0 \text { for }(t, x) \in\left[t_{0}, t_{0}+T_{0}\right] \times F .
\end{aligned}
$$


$\left(A_{7}\right) \quad F_{*}=\left\{a \in F_{0}: \frac{x_{0}^{i}-a}{k} \in F \quad(i=1,2, \ldots), \lim _{h \rightarrow 0^{+}} \inf \frac{1}{h}\left\|a+h f\left(t_{0}, a\right)-\frac{x_{0}^{1}-a}{k}\right\|=0\right.$ and $\lim _{h \rightarrow 0^{+}} \inf \frac{1}{h}\left\|\frac{x_{0}^{i-1}-a}{k}+h f\left(t, \frac{x_{0}^{i-1}-a}{k}\right)-\frac{x_{0}^{i}-a}{k}\right\|=0$ for $t \in\left(t_{0}, t_{0}+T\right]$, $(i=2,3, \ldots)\} \neq 0$.

$\left(A_{8}\right) \quad\left\{\epsilon_{n}\right\}_{n=1}^{\infty}$ is a sequence of numbers belonging to the interval $(0,1)$ and satisfying the condition $\lim _{n \rightarrow \infty} \epsilon_{n}=0$.

Then, for each natural $n$, problem (6) has $\epsilon_{n}$-approximate solution $x_{n}(t)$ on $\left[t_{0}, t_{0}+T\right]$ into $B\left(x_{0}, r\right)$ such that the following conditions hold:

There is a sequence $\left\{t_{i}^{n}\right\}_{i=0}^{\infty}$ in $\left[t_{0}, t_{0}+T\right]$ such that

(ii) $\quad x_{n}\left(t_{0}\right) \in F_{*}, x_{n}\left(t_{0}\right)+k x_{n}\left(t_{i}^{n}\right)=x_{0}^{i} \in F_{0} \backslash\left\{x_{0}\right\},(i=1,2, \ldots), x_{n}\left(t_{0}\right)+k x_{n}\left(t_{0}+T\right)$ $=x_{0} \in F_{0}$ and $\left\|x_{n}(t)-x_{n}(s)\right\| \leq M|t-s|$ for $t, s \in\left[t_{0}, t_{0}+T\right]$,

(iii) $x_{n}\left(t_{i}^{n}\right) \in F_{0}$ and $x_{n}(t)$ is linear on $\left[t_{i-1}^{n}, t_{i}^{n}\right](i=1,2, \ldots)$,

(iv) if $t \in\left(t_{i-1}^{n}, t_{i}^{n}\right)$, then $\left\|x_{n}^{\prime}(t)-f\left(t_{i-1}^{n}, x_{i-1}^{n}\right)\right\| \leq \epsilon_{n}(i=1,2, \ldots)$,

(v) if $\quad(t, y) \in\left[t_{i-1}^{n}, t_{i}^{n}\right] \times F_{0}$, with $\quad\left\|y-x_{n}\left(t_{i-1}^{n}\right)\right\| \leq M\left(t_{i}^{n}-t_{i-1}^{n}\right)$, then $\left\|f(t, y)-f\left(t_{i-1}^{n}, x_{n}\left(t_{i-1}^{n}\right)\right)\right\| \leq \epsilon_{n}(i=1,2, \ldots)$.

Proof: Let $n$ be an arbitrary fixed natural number. We shall construct sequences $x_{n}(t)$ and $\left\{t_{i}^{n}\right\}_{i=0}^{\infty}$ by induction on $i$.

First, we shall construct $\epsilon_{n}$-approximate solution $x_{n}(t)$ on $\left[t_{0}, t_{1}^{n}\right]$. For this purpose let

$$
t_{0}^{n}:=t_{0}
$$

and let $x_{n}\left(t_{0}\right)$ be an arbitrary chosen fixed element on $F_{*}$, i.e.,

$$
\begin{gathered}
x_{n}\left(t_{0}\right) \in F_{0} \text { and } \frac{x_{0}^{i}-x_{n}\left(t_{0}\right)}{k} \in F(i=1,2, \ldots), \\
\lim _{h \rightarrow 0^{+}} \inf \frac{1}{h}\left\|x_{n}\left(t_{0}\right)+h f\left(t_{0}, x_{n}\left(t_{0}\right)\right)-\frac{x_{0}^{1}-x_{n}\left(t_{0}\right)}{k}\right\|=0
\end{gathered}
$$

and

$$
\begin{gathered}
\lim _{h \rightarrow 0^{+}} \inf \frac{1}{h}\left\|\frac{x_{0}^{i-1}-x_{n}\left(t_{0}\right)}{k}+h f\left(t, \frac{x_{0}^{i-1}-x_{n}\left(t_{0}\right)}{k}\right)-\frac{x_{0}^{i}-x_{n}\left(t_{0}\right)}{k}\right\|=0 \\
\text { for } t \in\left(t_{0}, t_{0}+T\right](i=2,3, \ldots) .
\end{gathered}
$$

This choice of $x_{n}\left(t_{0}\right)$ is possible according to Assumption $\left(A_{7}\right)$.

Next, choose 


$$
\delta_{1}^{n} \in\left[0, \epsilon_{n}\right]
$$

such that $\delta_{1}^{n}$ is the largest number such that the following conditions hold:

$\left(a_{1}\right) \quad \delta_{1}^{n} \leq T$,

$\left(b_{1}\right)$ if $t \in\left[t_{0}, t_{0}+\delta_{1}^{n}\right]$ and $y \in F_{0}$ with $\left\|y-x_{n}\left(t_{0}\right)\right\| \leq M \delta_{1}^{n}$ then $\| f(t, y)-$ $f\left(t_{0}, x_{n}\left(t_{0}\right)\right) \| \leq \epsilon_{n}$,

$\left(c_{1}\right) \quad d\left(x_{n}\left(t_{0}\right)+\delta_{1}^{n} f\left(t_{0}, x_{n}\left(t_{0}\right)\right), F\right) \leq \frac{{ }^{e} n}{2} \delta_{1}^{n}$,

and

$$
\left(d_{1}\right) \quad\left\|x_{n}\left(t_{0}\right)+\delta_{1}^{n} f\left(t_{0}, x_{n}\left(t_{0}\right)\right)-\frac{x_{0}^{1}-x_{n}\left(t_{0}\right)}{k}\right\| \leq \epsilon_{n} \delta_{1}^{n} .
$$

The above choice is possible, by the fact that $f \in C\left(\left[t_{0}, t_{0}+T_{0}\right] \times F, E\right)$, according to Assumption $\left(A_{6}\right)$ and by $(86)$.

Now, define

$$
t_{1}^{n}=t_{0}+\delta_{1}^{n}
$$

and

$$
x_{n}\left(t_{1}^{n}\right):=\frac{x_{0}^{1}-x_{n}\left(t_{0}\right)}{k} .
$$

Since $\delta_{1}^{n}>0$, then, from (10), $t_{1}^{n}>t_{0}$ and, consequently, by (7), (9) and (10), condition (i) holds for $i=1$.

Moreover, by (11) and ( $8 a)$,

$$
x_{n}\left(t_{1}^{n}\right) \in F .
$$

Additionally, from $\left(d_{1}\right)$ and from (10)-(12),

$$
\left\|x_{n}\left(t_{0}\right)+\left(t_{1}^{n}-t_{0}\right) f\left(t_{0}, x_{n}\left(t_{0}\right)\right)-x_{n}\left(t_{1}^{n}\right)\right\| \leq \epsilon_{n}\left(t_{1}^{n}-t_{0}\right) .
$$

Next, define

$$
x_{n}(t)=\frac{x_{n}\left(t_{1}^{n}\right)-x_{n}\left(t_{0}\right)}{t_{1}^{n}-t_{0}}\left(t-t_{0}\right)+x_{n}\left(t_{0}\right) \text { for } t \in\left[t_{0}, t_{1}^{n}\right] .
$$

If $t, s \in\left[t_{0}, t_{1}^{n}\right]$, then by (14) and (13), by the assumption that $\left\{\epsilon_{n}\right\} \subset(0,1)$, and by Assumption $\left(A_{4}\right)$,

$$
\begin{aligned}
\left\|x_{n}(t)-x_{n}(s)\right\| & \leq \frac{\left\|x_{n}\left(t_{1}^{n}\right)-x_{n}\left(t_{0}\right)\right\|}{t_{1}^{n}-t_{0}}|t-s| \\
& \leq\left[\left\|f\left(t_{0}, x_{n}\left(t_{0}\right)\right)\right\|+\epsilon_{n}\right]|t-s| \\
& \leq\left[\left\|f\left(t_{0}, x_{n}\left(t_{0}\right)\right)\right\|+1\right]|t-s|
\end{aligned}
$$




$$
\leq M|t-s|
$$

which shows that $x_{n}(t)$ satisfies the Lipschitz condition on $\left[t_{0}, t_{1}^{n}\right]$. This together with $(8 a)$, (11) and Assumption $\left(A_{1}\right)$ means that condition(ii) holds for $i=1$.

Now, we will show that $x_{n}\left(t_{1}^{n}\right) \in F_{0}$. For this purpose observe that from (11), (4), $(15),(10)$ and $\left(a_{1}\right)$

$$
\begin{gathered}
\left\|x_{n}\left(t_{1}^{n}\right)-x_{0}\right\| \leq\left\|x_{n}\left(t_{1}^{n}\right)-x_{0}^{1}\right\|+\left\|x_{0}-x_{0}^{1}\right\| \\
\leq\left\|x_{n}\left(t_{1}^{n}\right)-x_{n}\left(t_{0}\right)-k x_{n}\left(t_{1}^{n}\right)\right\|+\epsilon \\
\leq M\left(t_{1}^{n}-t_{0}\right)+|k|\left\|x_{n}\left(t_{1}^{n}\right)\right\|+\epsilon \\
\leq M T+|k|\left\|x_{n}\left(t_{1}^{n}\right)\right\|+\epsilon .
\end{gathered}
$$

Simultaneously, by (11),

$$
\left\|x_{n}\left(t_{0}\right)\right\| \leq\left\|x_{0}^{1}\right\|+|k|\left\|x_{n}\left(t_{1}^{n}\right)\right\|
$$

and, by (15), (10) and $\left(a_{1}\right)$,

$$
\left\|x_{n}\left(t_{1}^{n}\right)-x_{n}\left(t_{0}\right)\right\| \leq M T .
$$

Consequently,

$$
\left\|x_{n}\left(t_{1}^{n}\right)\right\| \leq M T+\left\|x_{n}\left(t_{0}\right)\right\| .
$$

Therefore, from (18) and (17),

$$
\left\|x_{n}\left(t_{1}^{n}\right)\right\| \leq M T+\left\|x_{0}^{1}\right\|+|k|\left\|x_{n}\left(t_{1}^{n}\right)\right\| .
$$

Hence, by Assumption $\left(A_{2}\right)$,

$$
\left\|x_{n}\left(t_{1}^{n}\right)\right\| \leq \frac{M T+\left\|x_{0}^{1}\right\|}{1-|k|}
$$

Then, from (16), (19), (2) and from Assumption $\left(A_{5}\right)$,

$$
\begin{gathered}
\left\|x_{n}\left(t_{1}^{n}\right)-x_{0}\right\| \leq M T+|k| \frac{M T+\left\|x_{0}^{1}\right\|}{1-|k|}+\epsilon \\
=\frac{M}{1-|k|} T+\frac{|k|}{1-|k|}\left\|x_{0}^{1}\right\|+\epsilon \\
\leq \frac{M}{1-|k|} T+\frac{|k|}{1-|k|}\left\|x_{0}\right\|+\epsilon \\
\leq \frac{M}{1-|k|}\left[\frac{r-\epsilon}{M}(1-|k|)-\frac{\left\|x_{0}\right\|}{M}|k|\right]+\frac{|k|}{1-|k|}\left\|x_{0}\right\|+\epsilon
\end{gathered}
$$




$$
=r-\epsilon-\frac{|k|}{1-|k|}\left\|x_{0}\right\|+\frac{|k|}{1-|k|}\left\|x_{0}\right\|+c=r .
$$

Consequently, by (12), (20) and by the definition of $F_{0}, x_{n}\left(t_{1}^{n}\right) \in F_{0}$. This, together with (14), means that (iii) holds for $i=1$.

If $t \in\left(t_{0}, t_{1}^{n}\right)$, then $x^{\prime}(t)$ exists and hence, from (14) and (13),

$$
\left\|f\left(t_{0}, x_{n}\left(t_{0}\right)\right)-x_{n}^{\prime}(t)\right\| \leq \epsilon_{n} .
$$

Hence condition $(i v)$ holds for $t \in\left(t_{0}, t_{1}^{n}\right)$.

Finally, if $i=1$ then condition $(v)$ is a consequence of condition $\left(b_{1}\right)$.

Assume now that $i$ is a fixed natural number belonging to $N \backslash\{1\}, x_{n}(t)$ is defined on $\left[t_{0}, t_{i-1}^{n}\right]$, where $t_{i-1}^{n} \leq t_{0}+T$, and conditions $(i)-(v)$ of the thesis of Theorem 1 hold on $\left[t_{0}, t_{i-1}^{n}\right]$. Analogously, as in the proof of Theorem 1 for $i=1$, choose $\delta_{i}^{n} \in\left[0, \epsilon_{n}\right]$ such that $\delta_{i}^{n}$ is the largest number satisfying the conditions:

$\left(a_{i}\right) \quad t_{i-1}^{n}+\delta_{i}^{n} \leq t_{0}+T$,

$\left(b_{i}\right) \quad$ if $\quad t \in\left[t_{i-1}^{n}, t_{i-1}^{n}+\delta_{i}^{n}\right]$ and $y \in F_{0}$ with $\left\|y-x_{n}\left(t_{i-1}^{n}\right)\right\| \leq M \delta_{i}^{n}$, then $\left\|f(t, y)-f\left(t_{i-1}^{n}, x_{n}\left(t_{i-1}^{n}\right)\right)\right\| \leq \epsilon_{n}$,

$\left(c_{i}\right) \quad d\left(x_{n}\left(t_{i-1}^{n}\right)+\delta_{i}^{n} f\left(t_{i-1}^{n}, x_{n}\left(t_{i-1}^{n}\right)\right), F\right) \leq \frac{{ }^{\epsilon} n}{2} \delta_{i}^{n}$,

and

$\left(d_{i}\right) \quad\left\|x_{n}\left(t_{i-1}^{n}\right)+\delta_{i}^{n} f\left(t_{i-1}^{n}, x_{n}\left(t_{i-1}^{n}\right)\right)-\frac{x_{0}^{i}-x_{n}\left(t_{0}\right)}{k}\right\| \leq \epsilon_{n} \delta_{i}^{n}$.

Since $\delta_{i}^{n}>0$ and $\frac{x_{0}^{i}-x_{n}\left(t_{0}\right)}{k} \in F$, then let

$$
\begin{gathered}
t_{i}^{n}:=t_{i-1}^{n}+\delta_{i}^{n}, \\
x_{n}\left(t_{i}^{n}\right):=\frac{x_{0}^{i}-x_{n}\left(t_{0}\right)}{k}
\end{gathered}
$$

and

$$
x_{n}(t):=\frac{x_{n}\left(t_{i}^{n}\right)-x_{n}\left(t_{i-1}^{n}\right)}{t_{i}^{n}-t_{i-1}^{n}}\left(t-t_{i-1}^{n}\right)+x_{n}\left(t_{i-1}^{n}\right) \text { for } t \in\left[t_{i-1}^{n}, t_{i}^{n}\right]
$$

Using an argument similar to the first part of the proof we obtain properties $(i)-(v)$ of the thesis of Theorem 1 for $t \in\left[t_{0}, t_{i}^{n}\right]$. Particularly, if $t, s \in\left[t_{i-1}^{n}, t_{i}^{n}\right]$, then by (23), (22), (21), $\left(d_{i}\right)$, by the assumption that $\left\{\epsilon_{n}\right\} \subset(0,1)$, and by Assumption $\left(A_{4}\right)$,

$$
\begin{gathered}
\left\|x_{n}(t)-x_{n}(s)\right\| \leq \frac{\left\|x_{n}\left(t_{i}^{n}\right)-x_{n}\left(t_{i-1}^{n}\right)\right\|}{t_{i}^{n}-t_{i-1}^{n}}|t-s| \\
\leq\left[\left\|f\left(t_{i-1}^{n}, x_{n}\left(t_{i-1}^{n}\right)\right)\right\|+\epsilon_{n}\right]|t-s|
\end{gathered}
$$




$$
\begin{gathered}
\leq\left[\left\|f\left(t_{i-1}^{n}, x_{n}\left(t_{i-1}^{n}\right)\right)\right\|+1\right]|t-s| \\
\leq M|t-s| .
\end{gathered}
$$

This shows that $x_{n}(t)$ satisfies the Lipschitz condition on $\left[t_{i-1}^{n}, t_{i}^{n}\right]$. Therefore, to prove the Lipschitz condition on $\left[t_{0}, t_{i}^{n}\right]$, it is enough to prove this condition for

$$
t<s, t \in\left[t_{0}, t_{i-1}^{n}\right], s \in\left(t_{i-1}^{n}, t_{i}^{n}\right]
$$

Since

$$
\begin{gathered}
\mid x_{n}(t)-x_{n}(s)\|\leq\| x_{n}(t)-x_{n}\left(t_{i-1}^{n}\right)\|+\| x_{n}\left(t_{i-1}^{n}\right)-x_{n}(s) \| \\
\leq M\left(t_{i-1}^{n}-t\right)+M\left(s-t_{i-1}^{n}\right)=M(s-t)=M|t-s|
\end{gathered}
$$

for $t, s$ satisfying (25), then $x_{n}(t)$ satisfies the Lipschitz condition on $\left[t_{0}, t_{i}^{n}\right]$.

To show that $x_{n}\left(t_{i}^{n}\right) \in F_{0}$, observe that, from (22) and (4), from (24) for $t, s \in\left[t_{0}, t_{i}^{n}\right]$, and from (21) and $\left(a_{i}\right)$,

$$
\left\|x_{n}\left(t_{i}^{n}\right)-x_{0}\right\| \leq M T+|k|\left\|x_{n}\left(t_{i}^{n}\right)\right\|+\epsilon .
$$

But, by (22),

$$
\left\|x_{n}\left(t_{0}\right)\right\| \leq\left\|x_{0}^{i}\right\|+|k|\left\|x_{n}\left(t_{i}^{n}\right)\right\| .
$$

Simultaneously, from (24) for $t, s \in\left[t_{0}, t_{i}^{n}\right],(21)$ and $\left(a_{i}\right)$,

$$
\left\|x_{n}\left(t_{i}^{n}\right)\right\| \leq M T+\left\|x_{n}\left(t_{0}\right)\right\| \text {. }
$$

Therefore, by (28) and (27),

$$
\left\|x_{n}\left(t_{i}^{n}\right)\right\| \leq M T+\left\|x_{0}^{i}\right\|+|k|\left\|x_{n}\left(t_{i}^{n}\right)\right\| .
$$

Hence, from Assumption $\left(A_{2}\right)$,

$$
\left\|x_{n}\left(t_{i}^{n}\right)\right\| \leq \frac{M T+\left\|x_{0}^{i}\right\|}{1-|k|}
$$

Then, by (26), (29), (2) and Assumption $\left(A_{5}\right)$,

$$
\begin{gathered}
\left\|x_{n}\left(t_{i}^{n}\right)-x_{0}\right\| \leq M T+|k| \frac{M T+\left\|x_{0}^{i}\right\|}{1-|k|}+\epsilon \\
\leq \frac{M}{1-|k|} T+\frac{|k|}{1-|k|}\left\|x_{0}\right\|+\epsilon \leq r .
\end{gathered}
$$

Consequently, from the fact that $x_{n}\left(t_{i}^{n}\right) \in F$, from (30) and from the definition of $F_{0}, x_{n}\left(t_{i}^{n}\right) \in F_{0}$. 
Arguing as in [3] (see [3], Section 2.6), we have that

$$
\lim _{i \rightarrow \infty} t_{i}^{n}=t_{0}+T
$$

and then

$$
x\left(t_{0}+T\right)=\lim _{i \rightarrow \infty} x_{n}\left(t_{i}^{n}\right)
$$

Therefore, there is an $\epsilon_{n}$-approximate solution $x_{n}(t)$ on $\left[t_{0}, t_{0}+T\right]$ into $B\left(x_{0}, r\right)$ such that conditions $(i)-(v)$ from the thesis of Theorem 1 hold.

Theorem 2: $\quad$ Suppose that the assumptions of Theorem 1 hold and that

$$
\lim _{n \rightarrow \infty} x_{n}(t)=x(t) \text { for } t \in\left[t_{0}, t_{0}+T\right] \text {. }
$$

Then $x(t)$ is a solution of problem (6) for $t \in\left[t_{0}, t_{0}+T\right]$.

Proof: Since the sequence $\left\{x_{n}(t)\right\}$ is equicontinuous for $t \in\left[t_{0}, t_{0}+T\right]$, by (ii) of the thesis of Theorem 1, it follows that $\left\{x_{n}(t)\right\}$ converges uniformly to $x(t)$ for $t \in\left[t_{0}, t_{0}+T\right]$ and that $x(t)$ is continuous for $t \in\left[t_{0}, t_{0}+T\right]$. Moreover, from theses $(i)$ and $(i i)$ of Theorem 1 ,

$$
x\left(t_{0}\right)+k x\left(t_{0}+T\right)=x_{0},
$$

and using a similar argument as in [3] (see [3], the proof of Lemma 2.6.1), we obtain that

$$
x(t)=x\left(t_{0}\right)+\int_{t_{0}}^{t} f(s, x(s)) d s \text { for } t \in\left[t_{0}, t_{0}+T\right] .
$$

This completes the proof of Theorem 2.

Finally, we will give the following:

Example 3: Let

$$
E:=\mathbb{R}^{2}, \quad F:=\mathbb{R} \times(-\infty, 0]
$$

and let $x_{0}=\left(x_{01}, x_{02}\right)$ be an arbitrary point belonging to $F$ such that $x_{0} \neq(0,0)$. Moreover, let $x_{0}^{1}=(0,0)$ and let $x_{0}^{i}=\left(x_{01}^{i}, x_{02}^{i}\right) \quad(i=2,3, \ldots)$ be an arbitrary sequence belonging to the segment $\left[x_{0}^{1}, x_{0}\right]$ and satisfying the conditions

$$
\mid x_{0}^{i}\|\leq\| x_{0}^{i+1}\|\leq\| x_{0} \| \text { for all } i=2,3, \ldots
$$

and 


$$
\left\|x_{0}^{i}-x_{0}\right\| \underset{i \rightarrow \infty}{\longrightarrow} 0
$$

Choose two numbers $r$ and $\epsilon$ such that

$$
r>\epsilon>\left\|x_{0}^{1}-x_{0}\right\|=\left\|x_{0}\right\| .
$$

Then

$$
\left\|x_{0}^{i}-x_{0}\right\| \leq\left\|x_{0}^{1}-x_{0}\right\|<\epsilon \text { for all } i=2,3, \ldots
$$

and, consequently, Assumption $\left(A_{1}\right)$ holds.

Let $k$ be a real constant satisfying the condition

$$
0<|k|<\frac{r-\epsilon}{r-\epsilon+\left\|x_{0}\right\|}
$$

let $t_{0}$ be a real constant, let $T_{0}$ be a positive constant and $M$ be a constant such that $M>1$.

Introduce an arbitrary function $f$ belonging to $C\left(\left[t_{0}, t_{0}+T_{0}\right] \times F, E\right)$ and satisfying the following conditions:

(i) $\lim _{h \rightarrow 0^{+}} \inf \frac{1}{h} d(x+h f(t, x), F)=0$ for $(t, x) \in\left[t_{0}, t_{0}+T_{0}\right] \times F$,

(ii) $\quad f\left(t_{0}, h b\right):=-b-\frac{b}{k}$

and

$$
f\left(t, \frac{x_{0}^{i-1}-h b}{k}\right):=-\frac{x_{0}^{i-1}-x_{0}^{i}}{h k} \quad(i=2,3, \ldots),
$$

where $t \in\left(t_{0}, t_{0}+T\right], T:=\min \left\{T_{0}, \frac{r-\epsilon}{M}(1-|k|)-\frac{\left\|x_{0}\right\|}{M}|k|\right\}, h>0$ and $b$ is an element of $F$ such that

$$
\|b\| \leq \frac{|k|}{k+1}(M-1), h b \in F_{0} \text { and } \frac{x_{0}^{i-1}-h b}{k} \in F \backslash F_{0}(i=2,3, \ldots),
$$

(iii) $\|f(t, x)\| \leq M-1$ for $(t, x) \in\left(\left[t_{0}, t_{0}+T\right] \times F_{0}\right) \backslash\left\{\left(t_{0}, h b\right)\right\}$.

Let $a:=h b$. Then, from the above considerations,

(a) $a \in F_{0}$,

(b) $\frac{x_{0}^{i}-a}{k} \in F \backslash F_{0}(i=1,2, \ldots)$,

(c) $\left\|f\left(t_{0}, a\right)\right\|=\left\|-b-\frac{b}{k}\right\|=\frac{k+1}{|k|}\|b\| \leq M-1$,

(d) $\quad\left\|a+h f\left(t_{0}, a\right)-\frac{x_{0}^{1}-a}{k}\right\|=\left\|h b+h\left(-b-\frac{b}{k}\right)+\frac{h b}{k}\right\|=0$,

(e) $\quad\left\|\frac{x_{0}^{i-1}-a}{k}+h f\left(t, \frac{x_{0}^{i-1}-a}{k}\right)-\frac{x_{0}^{i}-a}{k}\right\|$

$$
=\left\|\frac{x_{0}^{i-1}-h b}{k}+h\left(\frac{x_{0}^{i-1}-x_{0}^{i}}{h k}\right)-\frac{x_{0}^{i}-h b}{k}\right\|
$$




$$
=\left\|\frac{x_{0}^{i-1}}{k}-\frac{x_{0}^{i-1}}{k}+\frac{x_{0}^{i}}{k}-\frac{x_{0}^{i}}{k}\right\|=0 .
$$

Consequently, Assumptions $\left(A_{1}\right)-\left(A_{7}\right)$ are satisfied. Particularly, function $f$, defined by formula (31) and (32) satisfies Assumption $\left(A_{7}\right)$.

\section{REFERENCES}

[1] Byszewski, L. and Lakshmikantham, V., Theorem about the existence and uniqueness of a solution of a nonlocal abstract Cauchy problem in a Banach spaces, Applicable Analysis 40, (1990), 11-19.

[2] Byszewski, L, Theorems about the existence and uniqueness of solutions of a semilinear evolution nonlocal Cauchy problem, Journal of Mathematical Analysis and Applications 162.2, (1991), 494-505.

[3] Lakshmikantham, L. and Leela, S., Nonlinear Differential Equations in Abstract Spaces, Pergamon Press, Oxford, New York, Toronto, Sydney, 1981. 


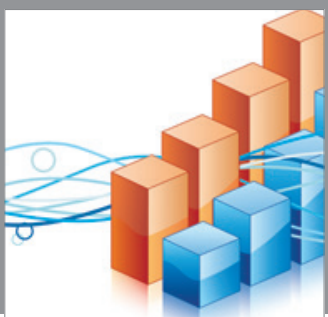

Advances in

Operations Research

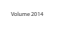

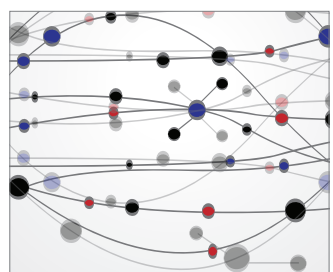

\section{The Scientific} World Journal
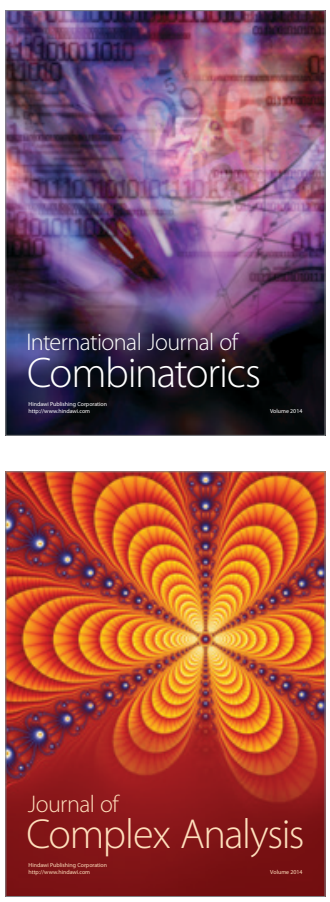

International Journal of

Mathematics and

Mathematical

Sciences
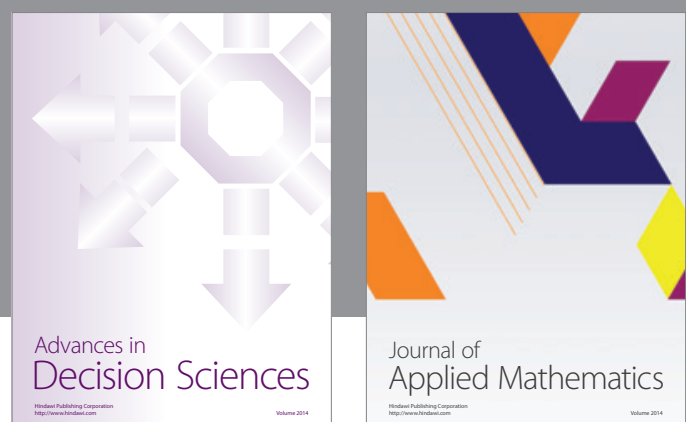

Journal of

Applied Mathematics
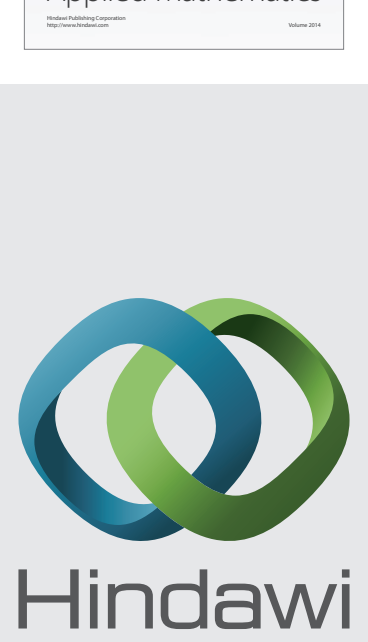

Submit your manuscripts at http://www.hindawi.com
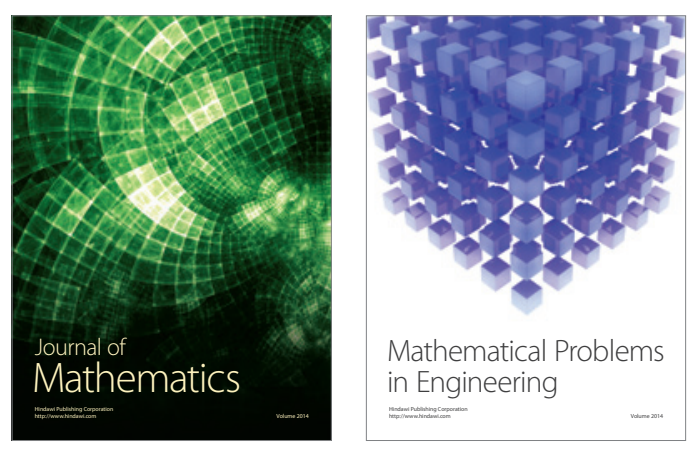

Mathematical Problems in Engineering
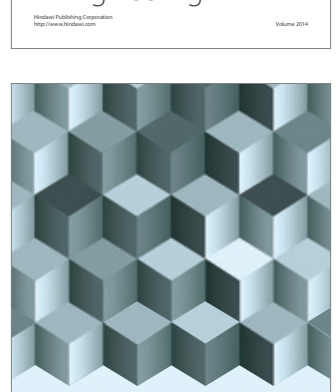

Journal of

Function Spaces
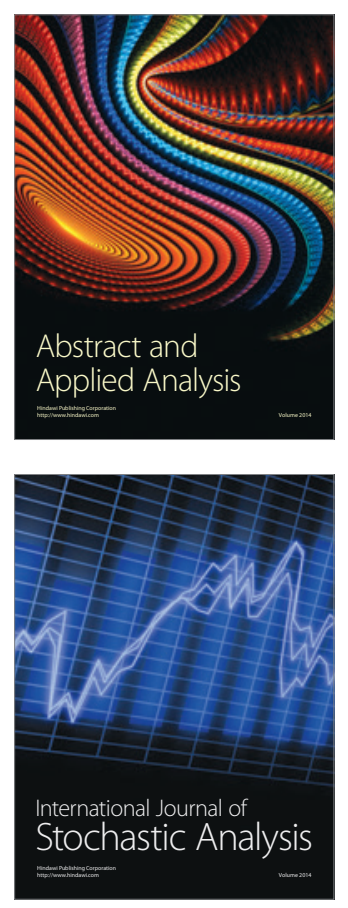

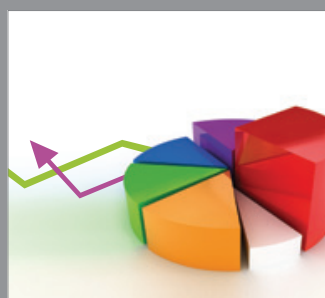

ournal of

Probability and Statistics

Promensencen
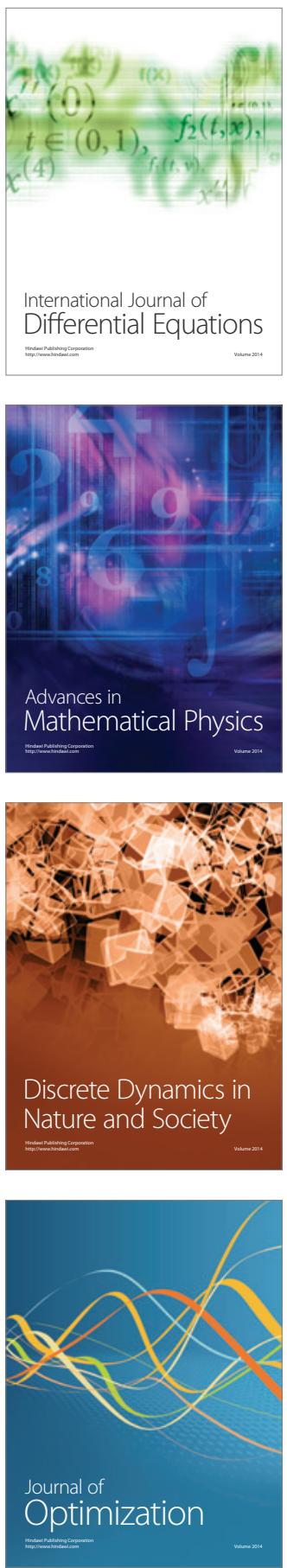